\title{
Glycosylation of serum proteins in inflammatory diseases
}

\author{
Olga Gornik and Gordan Lauc* \\ Department of Biochemistry and Molecular Biology, Faculty of Pharmacy and Biochemistry, University of Zagreb, \\ Zagreb, Croatia
}

\begin{abstract}
Inflammatory diseases are accompanied by numerous changes at the site of inflammation as well as many systemic physiological and biochemical changes. In the past two decades more and more attention is being paid to changes in glycosylation and in this review we describe some of the changes found on main serum proteins ( $\alpha 1$-acid glycoprotein, immunoglobulin $\mathrm{G}$, immunoglobulin A, transferrin, haptoglobin, $\alpha 2$-macroglobulin, C-reactive protein, and others). Molecular background and physiological importance of most of these changes are yet to be discovered, but it is evident that glycosylation plays an important role in the inflammatory response. Maybe the greatest value of these changes currently lays in their potential diagnostic and prognostic usage, either in combination with current diagnostic markers or on their own. However, determining glycan structures is still technically too complex for most clinical laboratories and further efforts have to be made to develop simple analytical tools to study changes in glycosylation.
\end{abstract}

Keywords: Glycosylation, inflammatory diseases, serum proteins, rheumatoid arthritis, systemic lupus erythematosus, pancreatitis, sepsis

\section{Introduction}

Inflammation is a complex biological response of an organism to harmful stimuli, such as pathogens, damaged cells, or irritants. This protective attempt to remove injurious stimuli and to initiate the process of healing is a part of almost all pathological conditions [1]. Both acute and chronic inflammation are highly complex and diverse processes and despite significant efforts invested in studying it, our knowledge how to diagnose, understand and control inflammatory response, is still very limited. Every inflammatory process is accompanied by numerous changes at the site of inflammation as well as many systemic physiological and biochemical changes [2], but in the past two decades more and more attention is being paid to changes in glycosylation [3,4]. Actually, the interaction between selectins and their glycoprotein ligands is

* Corresponding author. Faculty of Pharmacy and Biochemistry, Ante Kovačića 1, Zagreb, HR 10 000, Croatia. Tel.: +38514818 757; Fax: +385 14856 201; E-mail: glauc@pharma.hr. one of the crucial steps for the initiation of inflammation [5], but this has been extensively reviewed elsewhere [6] and is not subject of this review.

Glycosylation is the most diverse post-translational protein modification that provides numerous elaborate ways to modulate protein function [7-9]. Oligosaccharide structures are covalently bound to proteins through nitrogen atom of asparagine or oxygen atoms of serin or threonin side chains, forming $\mathrm{N}$-and O-linked glycoproteins, respectively [10]. N-linked oligosaccharides start with $\mathrm{N}$-acetylglucosamine linked to asparagine and have a glycan core made of five mannose units. They can further differ in branching, to form oligomannose, complex or hybrid types of glycans. Oligomannose type has two to six extra mannoses, while complex type glycans have two or more branches with at least one $\mathrm{N}$-acetylglucosamine and galactose and possibly one sialic acid on each branch. Hybrid type of glycans is a mixture of two types and has one branch of complex structure and one, or more, oligomannose branches (Fig. 1).

Glycans can be present in various structural forms on the same protein, at the same glycosylation site, re- 

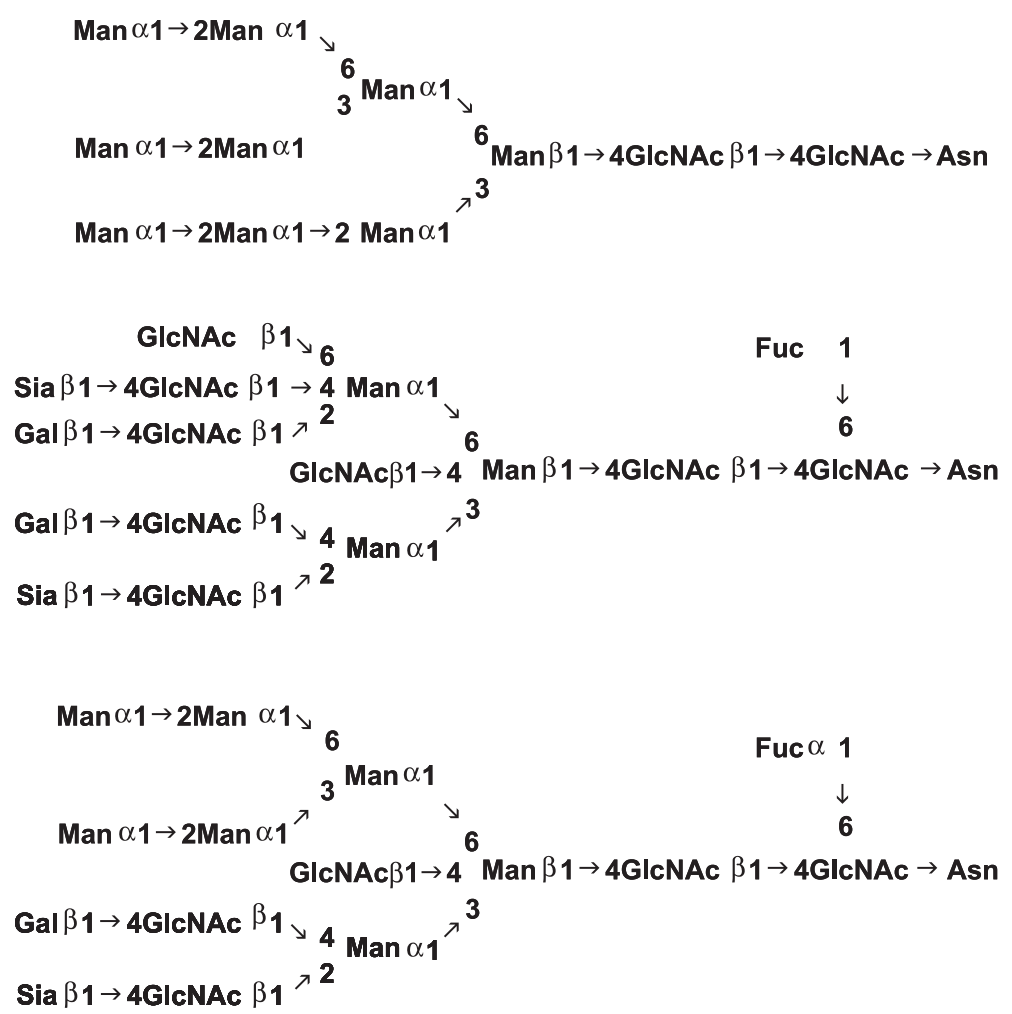

Fig. 1. Examples of oligomannose (top), complex (middle) and hybrid (bottom) glycans. All branches of an oligomannose type glycan end in mannoses. Complex type glycans have two or more branches with at least one $\mathrm{N}$-acetylglucosamine and galactose and possibly one sialic acid on each branch. Hybrid type of glycans is a mixture of two types and has one branch of complex structure and one, or more, oligomannose branches.

sulting in different glycoforms of the same molecule. It is considered that these changes reflect the origin of the molecule, telling about physiological and biochemical condition of an organism at the moment of the release of the exact molecule. The most important feature of glycoproteins is their heterogeneity. It can be expressed from minor to considerable differences through higher branching, loss of monosaccharides from one of glycan branches, through absence or presence of certain monosaccharide such as sialic acid, fucose, $\mathrm{N}$ acetylglucosamine or through type of linkage between sugars.

Many diseases are associated with changes in glycan structures [11]. Since there is no genetic blueprint for glycans, individual glycan structures vary depending on the current level of expression and intracellular localization of biosynthetic enzymes (glycosyltransferases and glycosidases). Consequently, altered glycan structures are often attached to the same protein backbone as a consequence of a patophysiological processes occurring in a cell that produces the protein. These alterations can be very specific, and studies of serum pro- tein glycosylation offer a good basis for diagnosis and prognosis of many diseases.

Numerous changes in glycosylation of serum proteins have been reported for inflammatory diseases. Most of these changes are studied in chronic inflammatory conditions, while information on glycosylation in acute inflammation is a bit modest, probably due to the fact that acute inflammation is difficult to catch in its starting point, since this highly dynamic and diverse process includes a cascade of biochemical events and involves many diverse systems. In this review we will present some of the numerous changes in glycosylation of selected serum proteins that were reported to be associated with different inflammatory diseases.

\section{2. $\alpha 1$-acid glycoprotein}

$\alpha 1$-acid glycoprotein (AGP) is a serum acute phase protein. Its concentration raises several fold during an acute phase reaction like severe burns or trauma, as well as under chronic pathological conditions like 
rheumatoid arthritis [12]. It possesses five N-linked complex type glycans $[13,14]$, which may be present as bi-, tri- and tetraantenary structures. Some of these structures may be $\alpha 1,3$-fucosylated to form a structure known as sialyl Lewis $\mathrm{X}$ antigen (Neu5Ac $\alpha 2,3 \mathrm{Gal}$ $\beta 1,4($ Fuc $\alpha 1,3)$ GlcNAc-R).

One of the most interesting features of AGP is that its glycosylation microheterogeneity was found to be altered in many diseases. AGP is a heavily glycosylated serum protein and its both binding and immunomodulatory functions seem to depend on its glycosylation. It represents a good model for glycosylation analysis and is thus, together with $\operatorname{IgG}$, maybe the most studied glycoprotein in different diseases. Among other physiological functions, AGP binds basic and neutral drugs and its binding activity is influenced by ionic interactions involving sialic acid and antennary structures [15].

Changes in biantennary structures of AGP, as well as $\alpha 1,3$ fucosylated $\mathrm{N}$-glycan structures, have been reported in patients with acute inflammation $[16,17]$ as well as with chronic conditions, such as reumathoid arthritis and diabetes mellitus [18,19]. First findings have mainly been made by using lectin affinity methods through increased binding of Concavalin A (Con A) [20] and Aleuria aurantia lectin (AAL) [21] to AGP in patients with inflammation. It is interesting to mention that studies on different inflammatory diseases showed different AGP microheterogeneity variants [12]. For instance, while a decrease in Con A reactivity was reported in ankylosing spondiliytis [22], Con A reactivity was normal in systemic lupus erythematosus [23] and inflammatory lung disease [24], and increased in acute pancreatitis [12]. However, all these findings can vary depending on the type of patients disease activity and presence of concurrent infection. In reumathoid arthritis patients it was shown that the reactivity of AGP with Con A correlates with disease activity [25], while a study on systemic lupus erythematosus showed an increased Con A reactivity in patients with concurrent infection [23]. Studies on chronic and acute infection showed a transition from initially elevated to decreased reactivity to Con A as disease became chronic [26].

Complete glycosylation patterns of AGP can be elucidated only by using more complex methods, such as HPLC (high performance liquid chromatography), HPAEC (high performance anion exchange chromatography), CE (capillary electrophoresis) and MS (mass spectrometry) techniques [17-19], and many findings made by lectin studies have also been confirmed by these methods. Relative increase of Con A reactive (biantennary) glycoforms of AGP was observed in patients with ulcerative colitis, a chronic inflammatory disease of unknown etiology, even after its remission. In acute inflammation the increase in biantennary structures was found to reach the maximum value in the early phase of inflammation (2nd day after surgical trauma), after which it decreased to control levels [21,27, 28 ]. Kinetics of this change in acute inflammation differs from the variation in the content of fucosylated glycans [21]. Maximum values of fucosylation, reached within the first few days, persisted even 10-30 days after patients were released from the hospital. Since these structures can suppress inflammation, it has been postulated that this increase might have beneficial effects by protecting the organism from overreaction that can occur during inflammation [29]. Since the enzyme responsible for the addition of such fucose is $\alpha 1-3 \mathrm{fu}-$ cosyltransferase, levels of this enzyme are crucial. A study on AGP suggested that inflammatory cytokines regulate the expression of $\alpha 1-3$ fucosyltransferase VI responsible for $\alpha 1-3$ fucosylation in liver tissue [17,21] as well as the expression of $\alpha 2-3$ sialyltransferase required for sialyl-Lewis X formation (since $\alpha 2-3$-linked sialylation is a prerequisite for $\alpha 1-3$ fucosylatation). Increase in biantennary structures over tri- and tetraantennary ones suggests the increased expression of $\beta 1,4$ galactosyltransferase, and the decreased expression of $\mathrm{N}$-acetylglucosaminyltransferases IV and/or $\mathrm{V}$ in inflamed hepatocytes.

Work on the prognostic value of $\alpha 1$-acid glycoprotein glycosylation in septic shock [30], indicated that a modest elevation in biantennary glycans in combination with a strong increase in sialyl-Lewis $\mathrm{X}$ was associated with higher mortality than a high transient increase in biantennary glycans with gradually increasing sialyl-Lewis X expression. This clearly demonstrates that the manner of changes in glycan structures can be associated with disease severity.

\section{Immunoglobulin G}

Immunoglobulin $\mathrm{G}(\mathrm{IgG})$ is a glycoprotein with a conserved $\mathrm{N}$-glycosylation site in the $\mathrm{Fc}$ region [31, 32], and variable glycosylation (either O- or N-linked) in the Fab region [32]. IgG molecules are glycosylated by biantennary complex glycan structures at Asn 297 in the Fc domain that can vary in the presence or absence of sialic acid, galactose, bisecting $\mathrm{N}$-acetylglucosamine or fucose (Fig. 2). Glycosylation of IgG molecules is essential for its binding to all $\mathrm{Fc} \gamma$ receptors $(\mathrm{Fc} \gamma \mathrm{R})$ 


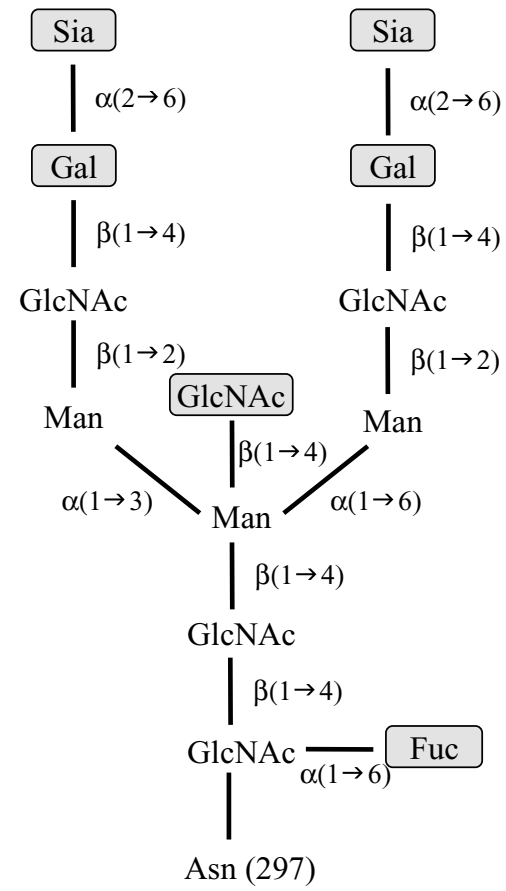

Fig. 2. The largest biantennary complex oligosaccharide found at the $\mathrm{Fc}$ region of human serum $\mathrm{IgG}$. There is a common pentasaccharide core containing two mannose (Man) residues attached to a $\beta$-mannosyl-di-N-acetylchitobiose unit. Individual glycans can lack one or more of the monosaccharides in striped boxes (sialic acid, galactose, bisecting $\mathrm{N}$-acetylglucosamine, or core fucose). Structure lacking both terminal galactose units is called G0 glycoform and is increased in rheumatoid arthritis and some other diseases.

through maintenance of an open conformation of the two heavy chains [33], and deglycosylated IgG antibodies are unable to mediate in vivo triggered inflammatory response [34]. One class of $\mathrm{Fc}-\mathrm{Fc} \gamma \mathrm{R}$ interactions generates pro-inflammatory effects of immune complexes and cytotoxic antibodies [35]. On the other hand, therapeutic intravenous gamma globulins and their Fc fragments are anti-inflammatory [35-38]. Intravenous gamma globulin is a purified $\mathrm{IgG}$ fraction obtained from the pooled serum of healthy donors and is used to treat inflammatory diseases through administration at high doses [39]. When this kind of antibodies was deglycosylated, they were no longer able to mediate anti-inflammatory activity in vivo [35]. The same effect can be accomplished by only desialylated intravenous gamma globulin, suggesting that sialic acid could be the sugar that is essential for its antiinflammatory activity [35].

Among all inflammatory conditions, rheumatoid arthritis is the one where glycosylation of $\mathrm{IgG}$ has been studied the most [40-42]. Decreased sialylation and galactosylation of Fc fragments of IgG molecules have been reported for this chronic inflammatory disease with autoimmune aspects in many studies using different analytic methods [43-45]. It was suggested that different glycoforms of IgG may interact differently with rheumatoid factor auto antibody (RF) in the manner that IgG molecules containing less terminal galactose are preferentially recognized by IgG RF [46]. Since $\mathrm{IgG}$ is less galactosylated in rheumatoid arthritis, and glycoforms having 0,1 or 2 galactose residues (G0, G1 and G2) are usually scanned for rheumatoid arthritis patients, it has been suggested to include quantification of G0 values in routine investigation of rheumatoid arthritis patients and to use G0 levels as prognostic marker for these patients. Very good agreement between different analytical methods ( 5 different chromatographic protocols and a lectin assay) for measuring G0 values in rheumatoid arthritis patients [41] and the fact that a decrease in galactosylation happens in the very early stage of rheumatoid arthritis provide further support for this suggestions. It is interesting to mention that an increase in G0 glycoforms for more than two standard deviations was shown to have positive predictive value of $80 \%$ for rheumatoid arthritis in an individual patient [47]. In the case when patient had both positive rheumatoid factor and increased G0 value this predictive value rose up to $94 \%$. The ratio of G0 was shown to be the best predictive marker for disease course [48] as well as the best marker of joint destruction [49, 50]. Similar changes have been observed in juvenile rheumatoid arthritis [51,52], although lectin study [53] reported no difference between galactosylation of juvenile rheumatoid arthritis patients and the control group until patients were divided in a group of those having acute phase of disease and those in remission. Patients with currently active juvenile rheumatoid arthritis had significantly lower levels of galactose than those in remission, in whom galactose levels were comparable to the control group. Interestingly, fucose levels in both groups were significantly higher than in controls, suggesting that fucosylation, and not only galactosylation of IgG might be an interesting diagnostic marker.

There is a great need to understand whether this altered glycosylation pattern in autoimmune disorders influences antibody-mediated effector functions. Some in vitro studies suggested that G0 antibodies gain the capacity to activate the complement pathway via mannose-binding lectin (MBL), which could contribute to antibody-mediated inflammation. Recent study in mice with a genetic deletion of MBL showed that the activity G0 antibodies is unimpaired in these mice [45] and is fully dependent on the presence of activating Fc 
receptors. Although this argues against the functional role of interactions between MBL and G0, it should not be neglected that roles of individual glycans (and glycoforms) can be significantly different in mouse and human.

In studies on small vessel vasculitides: Wegener's granulomatosis, microscopic polyangiitis and ChurgStrauss syndrome, that are characterized by circulating IgG of antineutrophil cytoplasmic antibodies, changes in IgG glycosylation have been reported as well [54]. Similar to rheumatoid arthritis and juvenile rheumatoid arthritis, these conditions are also accompanied by an increased amount of agalactosylated $\mathrm{IgG}$ molecules. Since the main pathophysiological model of these diseases is activation of neutrophiles by cytokines within the microvasculature, changes in IgG structure could contribute to increased activation of cytokines [54].

In Sjögren syndrome the same changes were observed in a certain subgroup of patients. In this subgroup decreased galactosylation, as well as increased level of bisecting $\mathrm{N}$-acetylglucosamine were found. Patients with normal IgG glycosylation profile had serologically negative RF factor and small risk for developing rheumatoid arthritis, while patients with G0 IgGs and high RF titer had increased risk for rheumatoid arthritis [55].

Glycosylation of IgG was also studied in many other non-rheumatic diseases, mainly malignant states, but since this is not the topic of this paper, changes found in these conditions will not be discussed here. An increase in the proportion of serum IgG molecules possessing an altered Fab glycosylation pattern (designated asymmetric antibodies) was also reported for chronic parasitic diseases [56]. The study on sera of rats in which an acute inflammatory response was produced by subcutaneous inoculation of turpentine oil [56] also showed an alteration in the synthesis and glycosylation of IgG. During acute inflammation there was a decrease in the synthesis of IgG which was not affected by prior oral administration of dexamethasone, however, the turpentine-induced increase in IgG binding to concanavalin A was found to be inhibited upon prior administration of the anti-inflammatory agent.

It is important to stress that changes in galactosylation of $\operatorname{IgG}$ are also present in normal, or better to say, physiological conditions. It is very well known that IgG galactosylation is age [57,58] and sex [59] related. It also changes during pregnancy, with reversible increase in galactosylation [60]. Iterleukin-6 (IL-6) is often mentioned as one of the possible modulation factors in IgG glycosylation, since activation of IL-6 correlates with decrease in galactosylation of IgG in animal model [61,62], as well as during pregnancy [63]. However, interleukin- 6 is probably just one of the numerous factors contributing to regulation of galactosylation and, in general, glycosylation of IgG as well as other serum proteins.

\section{Immunoglobulin A (IgA)}

Glycosylation also plays an important role in $\operatorname{IgA}$ nephrophaty, a form of glomerulonephritis, an inflammation of the glomeruli of the kidney characterized by deposition of the IgA antibody, especially $\operatorname{IgA} 1$ subclass, in glomeruli. IgA1 is rich in carbohydrates, carrying $\mathrm{N}$-linked moieties in common with IgG, but also O-linked sugars, which are rare in other serum proteins. Aberrant IgA1 O-linked glycosylation of the $\operatorname{Ig} \mathrm{A} 1$ hinge region is the most consistent finding of all abnormalities of the IgA immune system reported in IgA nephrophaty $[64,65]$. The defect comprises reduced galactosylation of O-linked $\mathrm{N}$ acetylgalactosamine residues with or without changes in the terminal sialylation of the O-linked sugars. These changes have great implications for the pathogenesis of IgA nephropathy, since O-linked sugars lie in an important functional location, close to the ligand recognition site of Fc receptors. Changes in the carbohydrates of IgA1 can therefore affect interactions with receptors and extracellular proteins [66], and lead to $\operatorname{IgA}$ immune complex formation and mesangial deposition, which can cause proliferation of mesangial cells and start inflammatory response.

\section{Transferrin}

Transferrin is a serum glycoprotein whose main role is transport of iron in blood [67]. It is a negative acute phase protein, meaning that its concentration decreases during acute phase response. Decreased transferrin values can also be found in the cases of liver diseases, chronic infections, malnutrition, protein losing enterophaty, trauma or any other severe disease.

Transferrin is made of one polypeptide chain with 679 amino acids and has two N-linked glycan structures on asparagines 413 and 611. Its glycan structures can be biantennary or triantennary and terminate in sialic acids. Changes in branching, fucosylation or sialylation of transferrin have been observed in many malignant [68,69], hereditary (galactosemia [70], CDG [71]) 
and other severe conditions [72], but in inflammatory diseases as well. Study on transferrin microheterogeneity patterns in sera of nonanemic rheumatoid arthritis patients, iron deficient rheumatoid arthritis patients and patients with the anemia of chronic disease showed increased branching of transferrin glycans in all rheumatoid arthritis groups which correlated to the disease activity (most pronounced in anemia of chronic disease) [73]. Increased branching of transferrin glycans, together with increased sialylation, was also reported for ulcerative colitis patient [74] where changes in glycosylation of $\alpha 1$-antichymotripsin and $\alpha 1$-acid glycoprotein were not observed. In this disease glycosylation patterns of transferrin did not differ according to the activity index of ulcerative colitis [74].

The majority of transferrin molecules $(85 \%)$ in the circulation of healthy individuals are glycosylated with two simple biantennary glycans terminating in $\alpha 2,6$ linked sialic acids and proper sialylation was found to be important for transferrin function [75-77]. Remaining $15 \%$ of transferrin molecules are penta- or trisialylated, while the proportion of less sialylated molecules is negligible [78]. The transferrin of lowered sialylation is called carbohydrate-deficient transferrin, and since its appearance reflect disturbances in glycosylation machinery it is already being routinely used to diagnose chronic alcoholism $[79,80]$ and congenital disorders of glycosylation [71].

Increased serum levels of carbohydrate-deficient transferrin have also been reported in patients with chronic obstructive pulmonary disease, using HPLC [81]. Levels of carbohydrate-deficient transferrin found did not depend on smoking status, although the cigarette smoking is the main risk for chronic obstructive pulmonary disease, and were in inverse correlation with lung function test values, suggesting that defects of glycosylation might be involved in the pathogenic mechanisms behind the development of this chronic pulmonary disease [81].

It was reported that elevated carbohydrate-deficient transferrin predicted prolonged intensive care unit stay in traumatized man [82] and major intercurrent complications were significantly increased in the high carbohydrate-deficient transferrin group (alcoholwithdrawal syndrome, tracheobronchitis, pneumonia, pancreatitis, sepsis, congestive heart failure...).

The work on transferrin sialylation in sepsis, using capillary zone electrophoresis, reported decreased sialylation in septic shock patients compared to healthy individuals as well as rapid decrease in sheep model of septic shock [77]. Our recent study in patients with sepsis indicated that transferrin sialylation decreases rapidly in septic patients (within first 24 hours), but then normalises to the initial values in the next few days [84]. Sialylation of transferrin apparently follows the intensity of inflammatory response and can predict its outcome. It seems that decrease in transferrin sialylation is a part of acute phase response in septic patients and that either more expressed decrease in transferrin sialylation, or no decrease at all, is associated with more severe ways of disease, such as severe sepsis and septic shock.

Different mechanisms of transferrin desialylation were proposed. Regarding the long transferrin half life of 16 days [83], rapid desialylation of transferrin can be explained either by higher activity of neuraminidases, or by higher clearens of highly sialylated transferrin from serum [77]. Same authors speculated that this phenomenon is specific for bacterial infection [77]. However, we observed the same pattern of sialylation changes in the early course of acute pancreatitis [84]. The fact that bacterial infection is not present in early acute pancreatitis argues against this theory, but concerning the role of transferrin as iron transporter [67], the possible physiological role of transferrin desialylation in infection should not be neglected. Bacteria need iron for their metabolism and transferrin is its main source in the host. Since desialylated transferrin has faster clearance from serum and infection is evolutionary the most usual trigger for inflammation, this mechanism probably developed as a part of the inflammatory response, regardless of actual presence or absence of infection.

\section{Haptoglobin}

Haptoglobin is another serum glycoprotein whose glycosylation was reported to be altered in rheumatoid arthritis [83]. Among these alterations are high levels of abnormally fucosylated forms found in the blood of individuals with active rheumatoid arthritis. These molecules can be detected by using fucose-specific lectin Lotus tetragonolobus and discriminate between active and inactive form of disease. However, elevation in fucosylation was not found to be disease specific, since it was also found in sero-negative patients. Elevation in haptoglobin fucosylation, together with higher branching, was also observed in patients with liver diseases initiated by alcohol abuse [86,87]. Alcohol abusers, patients with alcoholic cirrhosis and patients with primary biliary cirrhosis had changed haptoglobin glycosylation pattern, in contrast to patients with chronic active hepatitis [88]. 
Table 1

Common methods for studying glycosylation changes

\begin{tabular}{|c|c|c|c|c|}
\hline Method & Information Obtained & Advantages & Limitations & Conclusion \\
\hline Lectin affinity methods & $\begin{array}{l}\text { presence of specific } \\
\text { structure(s) }\end{array}$ & $\begin{array}{l}\text { easy to perform, uses na- } \\
\text { tive proteins, inexpensive }\end{array}$ & $\begin{array}{l}\text { provide limited informa- } \\
\text { tion, detects only some } \\
\text { structures }\end{array}$ & $\begin{array}{l}\text { applicable for screening } \\
\text { and preliminary tests }\end{array}$ \\
\hline $\begin{array}{l}\text { Lectin affinity } \\
\text { chromatography }\end{array}$ & & & $\begin{array}{l}\text { unspecific binding of all } \\
\text { proteins with certain gly- } \\
\text { can structure }\end{array}$ & $\begin{array}{l}\text { suitable for separating } \\
\text { purified proteins accord- } \\
\text { ing to glycosylation }\end{array}$ \\
\hline $\begin{array}{l}\text { Crossed affino- } \\
\text { immunoelectrophoresis }\end{array}$ & & $\begin{array}{l}\text { great flexibility (could in- } \\
\text { vestigate wide range of } \\
\text { proteins by using different } \\
\text { lectins and antibodies) }\end{array}$ & $\begin{array}{l}\text { cannot handle larger } \\
\text { number of samples, } \\
\text { semi-quantitative prob- } \\
\text { lems with reproducibility }\end{array}$ & \\
\hline $\begin{array}{l}\text { Electrophoresis }+ \\
\text { Western blotting }+ \\
\text { lectin detection }\end{array}$ & $\begin{array}{l}\text { protein separation and } \\
\text { lectin detection }\end{array}$ & $\begin{array}{l}\text { insufficient protein } \\
\text { separation }\end{array}$ & & \\
\hline $\begin{array}{l}\text { 2D electrophoresis }+ \\
\text { Western blotting }+ \\
\text { lectin detection }\end{array}$ & & $\begin{array}{l}\text { higher resolution of } \\
\text { protein separation }\end{array}$ & multiple steps included & \\
\hline $\begin{array}{l}\text { Enzyme linked lectin } \\
\text { assay (ELLA) }\end{array}$ & & fast, high throughput, & limited reliability & $\begin{array}{l}\text { suitable for high- } \\
\text { throughput screening }\end{array}$ \\
\hline $\begin{array}{l}\text { Chromatographic } \\
\text { methods }\end{array}$ & $\begin{array}{l}\text { type of oligosaccharides, } \\
\text { presence of specific } \\
\text { monosaccharides, type } \\
\text { and number of monosac- } \\
\text { charides, sequence and } \\
\text { linkages, positions of an- } \\
\text { tennae, anomeric } \\
\text { configurations }\end{array}$ & & $\begin{array}{l}\text { expensive, require good } \\
\text { analytical skills and data } \\
\text { interpretation }\end{array}$ & \\
\hline HPLC & & $\begin{array}{l}\text { Quantitative detailed in- } \\
\text { formation obtained, pos- } \\
\text { sible coupling with other } \\
\text { analytical methods }\end{array}$ & $\begin{array}{l}\text { requires purified gly- } \\
\text { can structures, demand- } \\
\text { ing sample preparation, } \\
\text { glycan labelling }\end{array}$ & $\begin{array}{l}\text { provides high amount of } \\
\text { information, especially } \\
\text { in combination with exo- } \\
\text { glycosidase sequencing }\end{array}$ \\
\hline HPAEC-PAD & & $\begin{array}{l}\text { no glycan labelling } \\
\text { required, quantitative }\end{array}$ & $\begin{array}{l}\text { requires purified glycan } \\
\text { structures }\end{array}$ & $\begin{array}{l}\text { good method for either } \\
\text { glycan or monosaccha- } \\
\text { ride content analysis }\end{array}$ \\
\hline Mass spectrometry & $\begin{array}{l}\text { type of oligosaccharides, } \\
\text { presence of specific } \\
\text { monosaccharide, type } \\
\text { and number of } \\
\text { monosaccharides, } \\
\text { sequence and linkages, } \\
\text { antennae positions, } \\
\text { anomeric configurations }\end{array}$ & $\begin{array}{l}\text { no glycan labelling } \\
\text { required, high sensitivity, } \\
\text { high amount of data, } \\
\text { reliable }\end{array}$ & $\begin{array}{l}\text { expensive equipment, re- } \\
\text { quire good analytical } \\
\text { skills and knowledge for } \\
\text { data interpretation, limit- } \\
\text { ed quantification }\end{array}$ & \\
\hline
\end{tabular}

\section{7. $\alpha 2$-Macroglobulin}

Using lectin blots in conjunction with peptide mapping, alpha 2-macroglobulin purified from systemic lupus erythematosus patients was shown to be abnormally glycosylated, suggesting the occurrence of complex glycosylation in this pathological condition [89]. When serum samples of normal donors, systemic lupus erythematosus patients, rheumatoid arthritis patients, a mixed connective tissue disease patient and a Sjogren's syndrome patient were analysed for carbohydrate content of alpha 2-macroglobulin it was not- ed that the concentration of total monosaccharides on alpha 2-macroglobulin purified from serum samples of systemic lupus erythematosus patients was significantly higher than in normal donors [89]. In the same study was also examined if there are any correlations between the levels of mannose and glucose on alpha 2-macroglobulin and systemic lupus erythematosus. The concentrations of mannose and galactose on alpha 2-macroglobulin from systemic lupus erythematosus patients were significantly higher than from normal donors, in contrast to concentration of glucose where no difference was found between exam- 
ined groups. These results suggested that quantification of carbohydrates in selected glycoproteins, such as alpha 2-macroglobulin, may be a novel and alternative clinical marker for systemic lupus erythematosus. Development of an enzyme-linked immunosorbent assay (ELISA) using a monoclonal antibody directed against abnormally glycosylated serum alpha2-macroglobulin which was capable of recognizing changes of glycosylation in systemic lupus erythematosus patients contributed further to this findings and may be useful in differential diagnosis [90].

\section{C-reactive protein}

Although C-reactive protein (CRP) is the "most popular" and the oldest molecular marker of acute phase response in both acute and chronic inflammation, work on glycosylation of this serum protein is very scarce. CRP is a pentraxin, calcium binding protein, whose value rises up to 100 times in the first 24 hours as response to initial stimulus, especially bacterial infection. It has been reported that CRPs show variation in both their amino acid sequences and glycosylation patterns in different pathological conditions [91]. These changes in tryptophan contents, together with glycosylation and specific sialylation changes play a contributory role in their binding characteristics (e.g. to antibodies, and other plasma proteins) [92].

Beside the difference in sialic acid content, it's different linkage was found in different diseases, by using Sambucus nigra agglutinin (recognizes $\alpha 2,6$ bound sialic acid) and Maackia amurensis (recognizes $\alpha 2,3$ bound sialic acid) lectins. CRPs from Visceral Leishmanisis, tuberculosis and Systemic Lupus Erythematosus contain $\alpha 2,3$ linked sialic acids, while proteins from some other diseases which are not of inflammatory character have $\alpha 2,6$ linked sialic acids [92]. Thus routine use of quantifying CRP may be further supplemented with determination of qualitative alterations of this protein to obtain a unique marker for diagnosis and monitoring of an acute phase response in inflammation.

\section{Other and total serum proteins}

Many studies done on protein glycosylation in inflammation involved total serum proteins, or combined the glycosylation patterns of few of them. As mentioned before, changes in sialylation of transferrin have been observed in septic patients as well as in ani- mal model of septic shock [77]. The same study also showed the increase in sialylation of total serum proteins. While following up sialylation of transferrin and total serum proteins during sepsis and acute pancreatitis we also observed an increase in sialylation of total serum proteins that occurred at the early course of disease, followed by normalization afterwards. The most probable explanation for this initial increase is the increased production of highly sialylated acute phase proteins such as $\alpha 1$-acid glycoprotein [2,93]. Further investigation on sialylation of plasma proteins in inflamed mice showed that the increase in sialylation involves all types of sialic acids $(\alpha 2,3, \alpha 2,6$ and $\alpha 2,8)$ [94].

Beside the increase in total sialylation, when acute phase response was stimulated in mice by turpentine oil injection, a decrease in total fucosylation was also reported to occur as an early event in the acute phase response [95]. $\alpha 1$-acid glycoprotein (a positive acute phase protein), $\alpha 1$-macroglobulin (a non acute phase protein) and $\alpha 1$-inhibitor3 (a negative acute phase protein) showed similar alterations in sialylation and fucosylation in this case, in contrast to $\alpha 2$-macroglobulin that contained no significant amount of fucose during acute phase response [95]. These studies demonstrated that changes mentioned happen on pre-existing plasma proteins (since they occur too rapidly for new protein synthesis to have visible effects) and that they also involve non-acute phase proteins. Secretion of sialyltransferases and fucosidases in plasma, reversible endocytosis of proteins or the action of membrane bound enzymes are only some of the possible mechanisms that could explain the observed effects.

Changes of glycosylation of serum proteins have also been detected in psoriatic arthritis where good correlation was observed between total Con A reactivity of serum and serum levels of CRP and IL-6 [96], which was discussed before as a putative regulator of glycosylation pattern of proteins upon inflammation. Increased reactivity to Con A for two serum proteins, AGP and antichymotripsin, was also detected in acute phase response after hip arthroplasty, with no correlation with protein concentrations [97].

Due to development of modern and sensitive techniques for studying glycan structures, the modern approach to study serum protein glycosylation patterns includes first the screening of total serum glycans and then the identification of exact serum proteins responsible for glycan structures involved in changes observed. This approach result in detailed information on glycan structures present in the serum sample and, although it is still time consuming, reveals many differ- 
ences. High performance liquid chromatography methods [98-100] and mass spectrometric methods [99,101] are techniques mostly used for this approach and are often further supplemented with different lectin methods (Table 1).

Mass spectrometric approach used to screen glycan structures in cirrhotic patients [101] showed an increase in bisecting $\mathrm{N}$-acetylglucosamine and core fucose, and revealed the presence of an important population of neutral oligosaccharides in this disease. HPLC analysis of $\mathrm{N}$-glycans from diabetic mice and humans with type 2 diabetes showed an increase in alpha1,6fucosylation [100], which was more expressed in mice. Study of total glycosylation profile of serum proteins in sepsis and acute pancreatitis also revealed many changes in these diseases as well as through their courses [102]. Glycans from these patients were analysed by normal phase and weak anion exchange HPLC, exoglycosidase digestions and mass spectrometry. Increase in the amount of fucosylated trisialylated structures and tetrasialylated structures, increase in ratio of outer arm to core fucose, changes in levels of mannose structures and in the degree of branching are just the most prominent changes found. The relative proportions of different glycans changed daily in studied patients and some differences were also observed between sepsis and pancreatitis, probably reflecting that in these two conditions the acute phase response is triggered by a different stimulus which is associated with different patterns of cytokines' production.

\section{Conclusions}

In this review we described some of the glycosylation changes found in different inflammatory conditions on main serum proteins. Molecular background for these changes and their role in pathophysiological processes are yet to be discovered, but it is evident that glycosylation plays an important role in inflammatory response. Maybe the greatest value of these changes currently lays in their potential diagnostic usage, either in combination with current diagnostic markers or on their own. Studying changes in glycan structures can help to early diagnose pathological conditions and in some cases also predict course of the disease. However, determining glycan structures is still technically too complex for most clinical laboratories and further efforts have to be made to develop simple analytical tools to study changes in glycosylation.

\section{Acknowledgements}

Work in author's laboratory is supported by grants \#219-0061194-2023 and \#006-0061194-1218 from the Croatian Ministry of Science, Education and Sport, and by EuroPharm grant from the European Commission.

\section{References}

[1] R.S. Cotran, Robbins pathologic basis of disease, 5th edition, 1994, Philadelphia: W.B. Saunders Co.

[2] C. Gabay and I. Kushner, Acute-phase proteins and other systemic responses to inflammation, N Engl J Med 340 (1999), $448-454$.

[3] A. Varki et al., Essentials of glycobiology, C.S. Harbor, ed., 1999, New York: Cold Spring Harbor Laboratory Press.

[4] J. Alper, Searching for medicine's sweet spot, Science 291 (2001), 2338-2343.

[5] M. Bevilacqua, E. Butcher, B. Furie, B. Furie, M. Gallatin, M. Gimbrone, J. Harlan, K. Kishimoto, L. Lasky, R. McEver et al., Selectins: a family of adhesion receptors, Cell $\mathbf{6 7}$ (1991), 233.

[6] S.R. Barthel, J.D. Gavino, L. Descheny and C.J. Dimitroff, Targeting selectins and selectin ligands in inflammation and cancer, Expert Opin Ther Targets 11 (2007), 1473-1491.

[7] K. Ohtsubo and J.D. Marth, Glycosylation in cellular mechanisms of health and disease, Cell 126 (2006), 855-867.

[8] G. Lauc, Sweet secret of the multicellular life, Biochim Biophys Acta 1760 (2006), 525-526.

[9] R.T. Lee, G. Lauc, and Y.C. Lee, Glycoproteomics: protein modifications for versatile functions. Meeting on glycoproteomics, EMBO Rep 6(2005),1018-22.

[10] R.G. Spiro, Protein glycosylation: nature, distribution, enzymatic formation, and disease implications of glycopeptide bonds, Glycobiology 12 (2002), 43R-56R.

[11] J. Axford, The impact of glycobiology on medicine, Trends Immunol 22 (2001), 237-239.

[12] G.A. Turner, N-glycosylation of serum proteins in disease and its investigation using lectins, Clin Chim Acta 208 (1992), 149-171.

[13] K. Schmid, R.B. Nimerg, A. Kimura, H. Yamaguchi and J.P. Binette, The carbohydrate units of human plasma alpha1-acid glycoprotein, Biochim Biophys Acta 492 (1977), 291-302.

[14] H. Yoshima, A. Matsumoto, T. Mizuochi, T. Kawasaki and A. Kobata, Comparative study of the carbohydrate moieties of rat and human plasma alpha 1-acid glycoproteins, J Biol Chem 256 (1981), 8476-8484.

[15] Y. Kuroda, A. Shibukawa and T. Nakagawa, Drug binding analysis of human alpha 1-acid glycoprotein using capillary electrophoresis, Yakugaku Zasshi 123 (2003), 781-788.

[16] E.C. Brinkman-van der Linden, P.F. de Haan, E.C. Havenaar and W. van Dijk, Inflammation-induced expression of sialyl LewisX is not restricted to alpha1-acid glycoprotein but also occurs to a lesser extent on alpha1-antichymotrypsin and haptoglobin, Glycoconj J 15 (1998), 177-182.

[17] K. Higai, Y. Aoki, Y. Azuma and K. Matsumoto, Glycosylation of site-specific glycans of alpha1-acid glycoprotein and alterations in acute and chronic inflammation, Biochim Biophys Acta 1725 (2005), 128-135.

[18] K. Higai, Y. Azuma, Y. Aoki and K. Matsumoto, Altered glycosylation of alpha1-acid glycoprotein in patients with 
inflammation and diabetes mellitus, Clin Chim Acta 329 (2003), 117-125.

[19] D.C. Poland, C.G. Schalkwijk, C.D. Stehouwer, C.A. Koeleman, B. van het Hofand W. van Dijk, Increased alpha3fucosylation of alpha1-acid glycoprotein in Type I diabetic patients is related to vascular function, Glycoconj $J \mathbf{~} \mathbf{8}$ (2001), 261-268.

[20] M.F. Bierhuizen, M. De Wit, C.A. Govers, W. Ferwerda, C. Koeleman, O. Pos and W. Van Dijk, Glycosylation of three molecular forms of human alpha 1-acid glycoprotein having different interactions with concanavalin A. Variations in the occurrence of di-, tri-, and tetraantennary glycans and the degree of sialylation, Eur J Biochem 175 (1988), 387-394.

[21] T.W. De Graaf, M.E. Van der Stelt, M.G. Anbergen and W. van Dijk, Inflammation-induced expression of sialyl Lewis $\mathrm{X}$-containing glycan structures on alpha 1-acid glycoprotein (orosomucoid) in human sera, J Exp Med 177 (1993), 657666.

[22] A. Mackiewicz, M.A. Khan, T.L. Reynolds, S. van der Linden and I. Kushner, Serum IgA, acute phase proteins, and glycosylation of alpha 1-acid glycoprotein in ankylosing spondylitis, Ann Rheum Dis 48 (1989), 99-103.

[23] A. Mackiewicz, R. Marcinkowska-Pieta, S. Ballou, S. Mackiewicz and I. Kushner, Microheterogeneity of alpha 1-acid glycoprotein in the detection of intercurrent infection in systemic lupus erythematosus, Arthritis Rheum 30 (1987), 513518.

[24] A.J. Bleasby, J.C. Knowles and N.J. Cooke, Microheterogeneity of alpha 1-acid glycoprotein: lack of discrimination between benign and malignant inflammatory disease of the lung, Clin Chim Acta 150 (1985), 231-235.

[25] A. Mackiewicz, T. Pawlowski, A. Mackiewicz-Pawlowska, K. Wiktorowicz and S. Mackiewicz, Microheterogeneity forms of alpha 1-acid glycoprotein as indicators of rheumatoid arthritis activity, Clin Chim Acta 163 (1987), 185-190.

[26] K. Fassbender, W. Zimmerli, R. Kissling, M. Sobieska, A. Aeschlimann, M. Kellner and W. Muller, Glycosylation of alpha 1-acid glycoprotein in relation to duration of disease in acute and chronic infection and inflammation, Clin Chim Acta 203 (1991), 315-327.

[27] O. Pos, M.E. van der Stelt, G.J. Wolbink, M.W. Nijsten, G.L. van der Tempel and W. van Dijk, Changes in the serum concentration and the glycosylation of human alpha 1-acid glycoprotein and alpha 1-protease inhibitor in severely burned persons: relation to interleukin-6 levels, Clin Exp Immunol 82 (1990), 579-582.

[28] W. van Dijk, E.C. Havenaar and E.C. Brinkman-van der Linden, Alpha 1-acid glycoprotein (orosomucoid): pathophysiological changes in glycosylation in relation to its function, Glycoconj J 12 (1995), 227-233.

[29] R.C. Bone, Toward a theory regarding the pathogenesis of the systemic inflammatory response syndrome: what we do and do not know about cytokine regulation, Crit Care Med 24 (1996), 163-172.

[30] E.C. Brinkman-van der Linden, E.C. van Ommen and W. van Dijk, Glycosylation of alpha 1-acid glycoprotein in septic shock: changes in degree of branching and in expression of sialyl Lewis(x) groups, Glycoconj J 13 (1996), 27-31.

[31] J. Deisenhofer, Crystallographic refinement and atomic models of a human $\mathrm{Fc}$ fragment and its complex with fragment B of protein A from Staphylococcus aureus at 2.9- and 2.8-A resolution, Biochemistry 20 (1981), 2361-2370.
[32] P.M. Rudd, R.J. Leatherbarrow, T.W. Rademacher and R.A. Dwek, Diversification of the IgG molecule by oligosaccharides, Mol Immunol 28 (1991), 1369-1378.

[33] P. Sondermann, J. Kaiser and U. Jacob, Molecular basis for immune complex recognition: a comparison of Fc-receptor structures, J Mol Biol 309 (2001), 737-749.

[34] F. Nimmerjahn and J.V. Ravetch, Fcgamma receptors: old friends and new family members, Immunity 24 (2006), 1928.

[35] Y. Kaneko, F. Nimmerjahn and J.V. Ravetch, Antiinflammatory activity of immunoglobulin $\mathrm{G}$ resulting from Fc sialylation, Science 313 (2006), 670-673.

[36] P. Imbach, S. Barandun, V. d'Apuzzo, C. Baumgartner, A. Hirt, A. Morell, E. Rossi, M. Schoni, M. Vest and H.P. Wagner, High-dose intravenous gammaglobulin for idiopathic thrombocytopenic purpura in childhood, Lancet 1 (1981), 1228-1231.

[37] A. Samuelsson, T.L. Towers and J.V. Ravetch, Antiinflammatory activity of IVIG mediated through the inhibitory Fc receptor, Science 291 (2001), 484-486.

[38] Y. Kaneko, F. Nimmerjahn, M.P. Madaio and J.V. Ravetch, Pathology and protection in nephrotoxic nephritis is determined by selective engagement of specific Fc receptors, $J$ Exp Med 203 (2006), 789-797.

[39] J.M. Dwyer, Manipulating the immune system with immune globulin, N Engl J Med 326 (1992), 107-116.

[40] M.T. Goodarzi, J.S. Axford, S.S. Varanasi, A. Alavi, G. Cunnane, O. Fitzgerald and G.A. Turner, Sialyl Lewis(x) expression on $\operatorname{IgG}$ in rheumatoid arthritis and other arthritic conditions: a preliminary study, Glycoconj J 15 (1998), 11491154.

[41] F.H. Routier, E.F. Hounsell, P.M. Rudd, N. Takahashi, A. Bond, F.C. Hay, A. Alavi, J.S. Axford and R. Jefferis, Quantitation of the oligosaccharides of human serum IgG from patients with rheumatoid arthritis: a critical evaluation of different methods, J Immunol Methods 213 (1998), 113-130.

[42] J.S. Axford, Glycosylation and rheumatic disease, Biochim Biophys Acta 1455 (1999), 219-229.

[43] A. Youings, S.C. Chang, R.A. Dwek and I.G. Scragg, Sitespecific glycosylation of human immunoglobulin $\mathrm{G}$ is altered in four rheumatoid arthritis patients, Biochem $J$ 314( $\mathrm{Pt} 2)$ (1996), 621-630.

[44] R.B. Parekh, R.A. Dwek, B.J. Sutton, D.L. Fernandes, A. Leung, D. Stanworth, T.W. Rademacher, T. Mizuochi, T. Taniguchi, K. Matsuta et al., Association of rheumatoid arthritis and primary osteoarthritis with changes in the glycosylation pattern of total serum IgG, Nature 316 (1985), 452-457.

[45] F. Nimmerjahn, R.M. Anthony and J.V. Ravetch, Agalactosylated IgG antibodies depend on cellular Fc receptors for in vivo activity, Proc Natl Acad Sci USA 104 (2007), 84338437

[46] C.T. Chou, Binding of rheumatoid and lupus synovial fluids and sera-derived human $\mathrm{IgG}$ rheumatoid factor to degalactosylated IgG, Arch Med Res 33 (2002), 541-544.

[47] A. Young, N. Sumar, K. Bodman, S. Goyal, H. Sinclair, I. Roitt and D. Isenberg, Agalactosyl IgG: an aid to differential diagnosis in early synovitis, Arthritis Rheum 34 (1991), 1425-1429.

[48] K. Bodman-Smith, N. Sumar, H. Sinclair, I. Roitt, D. Isenberg and A. Young, Agalactosyl IgG Gal(o)-an analysis of its clinical utility in the long-term follow-up of patients with rheumatoid arthritis, Br J Rheumatol 35 (1996), 1063-1066. 
[49] D. van Zeben, J.M. Hazes, A.H. Zwinderman, J.P. Vandenbroucke and F.C. Breedveld, The severity of rheumatoid arthritis: a 6-year followup study of younger women with symptoms of recent onset, J Rheumatol 21 (1994), 16201625.

[50] D. van Zeben, G.A. Rook, J.M. Hazes, A.H. Zwinderman, Y. Zhang, S. Ghelani, T.W. Rademacher and F.C. Breedveld, Early agalactosylation of IgG is associated with a more progressive disease course in patients with rheumatoid arthritis: results of a follow-up study, Br J Rheumatol 33 (1994), $36-43$.

[51] A. Bond, A. Alavi, J.S. Axford, B.E. Bourke, F.E. Bruckner, M.A. Kerr, J.D. Maxwell, K.J. Tweed, M.J. Weldon, P. Youinou and F.C. Hay, A detailed lectin analysis of IgG glycosylation, demonstrating disease specific changes in terminal galactose and $\mathrm{N}$-acetylglucosamine, J Autoimmun $\mathbf{1 0}$ (1997), 77-85.

[52] R.B. Parekh, I.M. Roitt, D.A. Isenberg, R.A. Dwek, B.M. Ansell and T.W. Rademacher, Galactosylation of IgG associated oligosaccharides: reduction in patients with adult and juvenile onset rheumatoid arthritis and relation to disease activity, Lancet 1 (1988), 966-969.

[53] M. Flogel, G. Lauc, I. Gornik and B. Macek, Fucosylation and galactosylation of IgG heavy chains differ between acute and remission phases of juvenile chronic arthritis, Clin Chem Lab Med 36 (1998), 99-102.

[54] M. Holland, K. Takada, T. Okumoto, N. Takahashi, K. Kato, D. Adu, A. Ben-Smith, L. Harper, C.O. Savage and R. Jefferis, Hypogalactosylation of serum IgG in patients with ANCA-associated systemic vasculitis, Clin Exp Immunol 129 (2002), 183-190.

[55] Y. Kuroda, M. Nakata, A. Makino, A. Matsumoto, K. Ohashi, K. Itahashi, F. Takeuchi, M. Goto, N. Kojima and T. Mizuochi, Structural studies on IgG oligosaccharides of patients with primary Sjogren's syndrome, Glycoconj J 19 (2002), 23-31.

[56] A. Canellada and R.A. Margni, Modified immunoglobulin G glycosylation pattern during turpentine-induced acute inflammation in rats, Medicina (B Aires) 62 (2002), 249-255.

[57] R. Parekh, I. Roitt, D. Isenberg, R. Dwek and T. Rademacher, Age-related galactosylation of the N-linked oligosaccharides of human serum IgG, J Exp Med 167 (1988), 1731-1736.

[58] N. Sumar, K.B. Bodman, T.W. Rademacher, R.A. Dwek, P. Williams, R.B. Parekh, J. Edge, G.A. Rook, D.A. Isenberg, F.C. Hay et al., Analysis of glycosylation changes in IgG using lectins, J Immunol Methods 131 (1990), 127-136.

[59] K. Shikata, T. Yasuda, F. Takeuchi, T. Konishi, M. Nakata and T. Mizuochi, Structural changes in the oligosaccharide moiety of human IgG with aging, Glycoconj J 15 (1998), 683-689.

[60] G.A. Rook, J. Steele, R. Brealey, A. Whyte, D. Isenberg, N. Sumar, J.L. Nelson, K.B. Bodman, A. Young, I.M. Roitt et al., Changes in IgG glycoform levels are associated with remission of arthritis during pregnancy, J Autoimmun 4 (1991), 779-794.

[61] Y. Hitsumoto, S.J. Thompson, Y.W. Zhang, G.A. Rook and C.J. Elson, Relationship between interleukin 6, agalactosyl IgG and pristane-induced arthritis, Autoimmunity 11 (1992), 247-254.

[62] S.J. Thompson, Y. Hitsumoto, Y.W. Zhang, G.A. Rook and C.J. Elson, Agalactosyl IgG in pristane-induced arthritis. Pregnancy affects the incidence and severity of arthritis and the glycosylation status of IgG, Clin Exp Immunol 89 (1992), 434-438.
[63] A. Alavi, N. Arden, T.D. Spector and J.S. Axford, Immunoglobulin G glycosylation and clinical outcome in rheumatoid arthritis during pregnancy, J Rheumatol 27 (2000), 1379-1385.

[64] J. Feehally and A.C. Allen, Pathogenesis of IgA nephropathy, Ann Med Interne (Paris) 150 (1999), 91-98.

[65] J. Barratt, A.C. Smith and J. Feehally, The pathogenic role of IgA1 O-linked glycosylation in the pathogenesis of IgA nephropathy, Nephrology (Carlton) 12 (2007), 275-284.

[66] J. Feehally and A.C. Allen, Structural features of $\operatorname{IgA}$ molecules which contribute to IgA nephropathy, J Nephrol 12 (1999), 59-65.

[67] G. de Jong, J.P. van Dijk and H.G. van Eijk, The biology of transferrin, Clin Chim Acta 190 (1990), 1-46.

[68] K. Yamashita, N. Koide, T. Endo, Y. Iwaki and A. Kobata, Altered glycosylation of serum transferrin of patients with hepatocellular carcinoma, J Biol Chem 264 (1989), 24152423.

[69] K. Matsumoto, Y. Maeda, S. Kato and H. Yuki, Alteration of asparagine-linked glycosylation in serum transferrin of patients with hepatocellular carcinoma, Clin Chim Acta 224 (1994), 1-8.

[70] L. Sturiale, R. Barone, A. Fiumara, M. Perez, M. Zaffanello, G. Sorge, L. Pavone, S. Tortorelli, J.F. O'Brien, J. Jaeken, and D. Garozzo, Hypoglycosylation with increased fucosylation and branching of serum transferrin N-glycans in untreated galactosemia, Glycobiology 15(2005),1268-76.

[71] M. Edwards, F. McKenzie, S. O'Callaghan, D. Somerset, P. Woodford, J. Spilsbury, M. Fietz and J. Fletcher, Prenatal diagnosis of congenital disorder of glycosylation type Ia (CDGIa) by cordocentesis and transferrin isoelectric focussing of serum of a 27 -week fetus with non-immune hydrops, Prenat Diagn 26 (2006), 985-988.

[72] T. Arndt, R. Hackler, T. Muller, T.O. Kleine and A.M. Gressner, Increased serum concentration of carbohydrate-deficient transferrin in patients with combined pancreas and kidney transplantation, Clin Chem 43 (1997), 344-351.

[73] R.A. Feelders, G. Vreugdenhil, G. de Jong, A.J. Swaak and H.G. van Eijk, Transferrin microheterogeneity in rheumatoid arthritis. Relation with disease activity and anemia of chronic disease, Rheumatol Int 12 (1992), 195-199.

[74] M. Grzymislawski, K. Derc, M. Sobieska and K. Wiktorowicz, Microheterogeneity of acute phase proteins in patients with ulcerative colitis, World J Gastroenterol 12 (2006), 5191-5195.

[75] Y. Beguin, G. Bergamaschi, H.A. Huebers and C.A. Finch, The behavior of asialotransferrin-iron in the rat, Am J Hematol 29 (1988), 204-210.

[76] J.R. Rudolph, E. Regoeczi, P.A. Chindemi and M.T. Debanne, Preferential hepatic uptake of iron from rat asialotransferrin: possible engagement of two receptors, Am J Physiol 251 (1986), G398-404.

[77] M. Piagnerelli, K.Z. Boudjeltia, V. Nuyens, D. De Backer, F. Su, Z. Wang, J.L. Vincent and M. Vanhaeverbeek, Rapid alterations in transferrin sialylation during sepsis, Shock $\mathbf{2 4}$ (2005), 48-52.

[78] G. de Jong and H.G. van Eijk, Microheterogeneity of human serum transferrin: a biological phenomenon studied by isoelectric focusing in immobilized $\mathrm{pH}$ gradients, Electrophoresis 9 (1988), 589-598.

[79] R.F. Anton, Carbohydrate-deficient transferrin for detection and monitoring of sustained heavy drinking. What have we learned? Where do we go from here? Alcohol 25 (2001), $185-188$. 
[80] P. Konig, H. Niederhofer, H. Steurer, R. Haller, R. Wolfle, H. Fritzsche and P. Weiss, Changes of carbohydrate-deficient transferrin in chronic alcoholism, Neuropsychobiology 32 (1995), 192-196.

[81] U. Nihlen, P. Montnemery, L.H. Lindholm and C.G. Lofdahl, Increased serum levels of carbohydrate-deficient transferrin in patients with chronic obstructive pulmonary disease, Scand J Clin Lab Invest 61 (2001), 341-347.

[82] C.D. Spies, M. Kissner, T. Neumann, S. Blum, C. Voigt, T. Funk, N. Runkel and F. Pragst, Elevated carbohydratedeficient transferrin predicts prolonged intensive care unit stay in traumatized men, Alcohol Alcohol 33 (1998), 661669.

[83] H. Stibler, Carbohydrate-deficient transferrin in serum: a new marker of potentially harmful alcohol consumption reviewed, Clin Chem 37 (1991), 2029-2037.

[84] O. Gornik, I. Gornik, V. Gašparović and G. Lauc, Change in transferrin sialylation is a potential prognostic marker for severity of acute pancreatitis, Clin Biochem 41 (2008), 504510.

[85] S. Thompson, E. Dargan, I.D. Griffiths, C.A. Kelly and G.A. Turner, The glycosylation of haptoglobin in rheumatoid arthritis, Clin Chim Acta 220 (1993), 107-114.

[86] A.C. Mann, S. Thompson, C.O. Record, C.H. Self and G.A Turner, Monosaccharide composition of haptoglobin purified from alcoholic cirrhotic and control sera determined by HPAE, Biochem Soc Trans 21 (1993), 214S.

[87] W. Chambers, S. Thompson, A.W. Skillen, C.O. Record and G.A. Turner, Abnormally fucosylated haptoglobin as a marker for alcoholic liver disease but not excessive alcohol consumption or non-alcoholic liver disease, Clin Chim Acta 219 (1993), 177-182.

[88] A.C. Mann, C.O. Record, C.H. Self and G.A. Turner, Monosaccharide composition of haptoglobin in liver diseases and alcohol abuse: large changes in glycosylation associated with alcoholic liver disease, Clin Chim Acta 227 (1994), 69-78.

[89] C. Panzironi, B. Silvestrini, M.Y. Mo, R. Lahita, D. Mruk and C.Y. Cheng, An increase in the carbohydrate moiety of alpha 2-macroglobulin is associated with systemic lupus erythematosus (SLE), Biochem Mol Biol Int 43 (1997), 13051322.

[90] N. Cazzolla, L. Saso, J. Grima, M.G. Leone, E. Grippa, C.Y. Cheng and B. Silvestrini, Development of an enzyme-linked immunosorbent assay, using a monoclonal antibody against alpha2-macroglobulin, for the diagnosis of systemic lupus erythematosus, Clin Biochem 32 (1999), 249-255.

[91] T. Das, A.K. Sen, T. Kempf, S.R. Pramanik, C. Mandal and C. Mandal, Induction of glycosylation in human C-reactive protein under different pathological conditions, Biochem $J$ 373 (2003), 345-355.

[92] T. Das, C. Mandal and C. Mandal, Variations in binding characteristics of glycosylated human C-reactive proteins in different pathological conditions, Glycoconj J 20 (2004), 537543.

[93] P. Sillanaukee, M. Ponnio and I.P. Jaaskelainen, Occurrence of sialic acid s in healthy humans and different disorders, Eur J Clin Invest 29 (1999), 413-425.

[94] Z. Yasukawa, C. Sato and K. Kitajima, Inflammationdependent changes in alpha2,3-, alpha2,6-, and alpha2,8sialic acid glycotopes on serum glycoproteins in mice, Glycobiology 15 (2005), 827-837.

[95] M.M. Chavan, P.D. Kawle and N.G. Mehta, Increased sialylation and defucosylation of plasma proteins are early events in the acute phase response, Glycobiology 15 (2005), 838848.

[96] L. Saso, G. Valentini, A.M. Giardino, A. Spadaro, V. Riccieri, A. Zoppini and B. Silvestrini, Changes of glycosylation of serum proteins in psoriatic arthritis, studied by enzymelinked lectin assay (ELLA), using concanavalin A, Biochem Mol Biol Int 46 (1998), 867-875.

[97] K. Fassbender, B. Gerber, U. Karrer, M. Sobieska, A. Aeschlimann and W. Muller, Glycosylation of acute phase proteins and interleukins following hip arthroplasty. Inflammation parameters studied in 10 patients, Acta Orthop Scand 64 (1993), 216-220.

[98] L. Royle, C.M. Radcliffe, R.A. Dwek and P.M. Rudd, Detailed structural analysis of $\mathrm{N}$-glycans released from glycoproteins in SDS-PAGE gel bands using HPLC combined with exoglycosidase array digestions, Methods Mol Biol 347 (2006), 125-143.

[99] E. Llop, R.G. Gallego, V. Belalcazar, G.J. Gerwig, J.P. Kamerling, J. Segura and J.A. Pascual, Evaluation of protein $\mathrm{N}$-glycosylation in 2-DE: Erythropoietin as a study case, Proteomics (2007).

[100] N. Itoh, S. Sakaue, H. Nakagawa, M. Kurogochi, H. Ohira, K. Deguchi, S. Nishimura and M. Nishimura, Analysis of Nglycan in serum glycoproteins from $\mathrm{db} / \mathrm{db}$ mice and humans with type 2 diabetes, Am J Physiol Endocrinol Metab 293 (2007), E1069-1077.

[101] W. Morelle, C. Flahaut, J.C. Michalski, A. Louvet, P. Mathurin and A. Klein, Mass spectrometric approach for screening modifications of total serum $\mathrm{N}$-glycome in human diseases: application to cirrhosis, Glycobiology 16 (2006), 281-293.

[102] O. Gornik, L. Royle, D.J. Harvey, C.M. Radcliffe, R. Saldova, R.A. Dwek, P. Rudd and G. Lauc, Changes of serum glycans during sepsis and acute pancreatitis, Glycobiology 17 (2007), 1321-1332. 


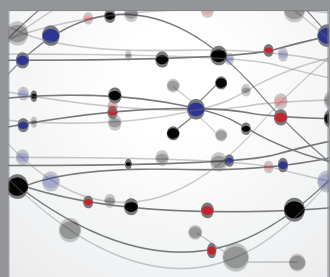

The Scientific World Journal
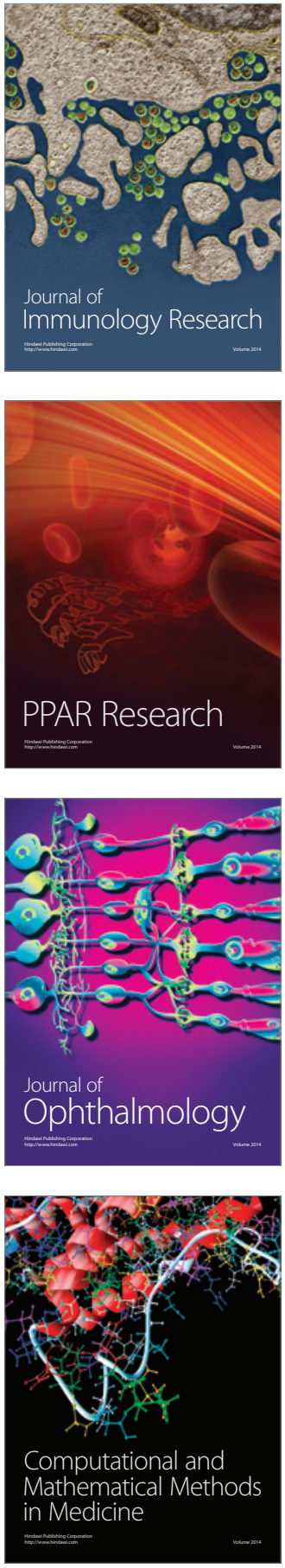

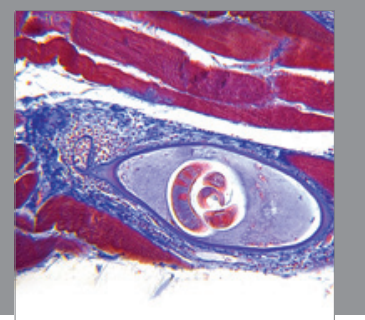

Gastroenterology

Research and Practice
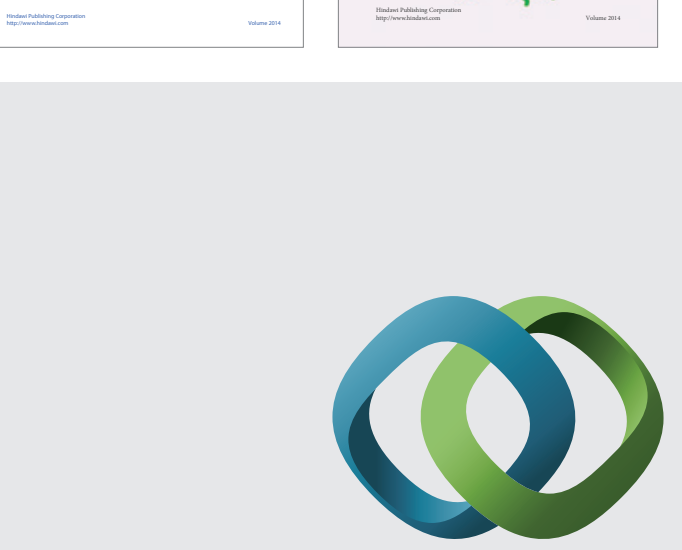

\section{Hindawi}

Submit your manuscripts at

http://www.hindawi.com
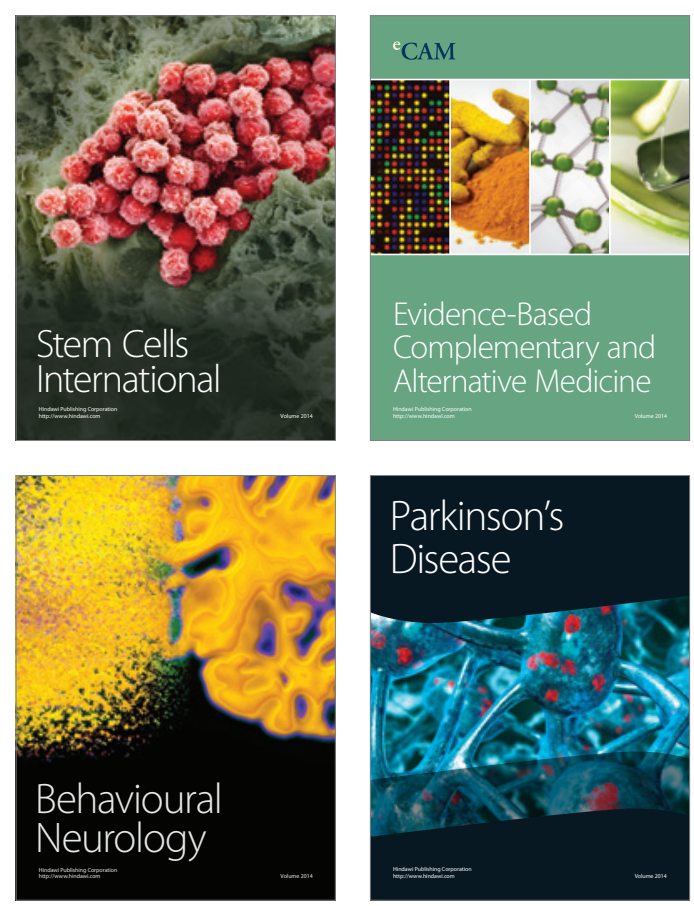

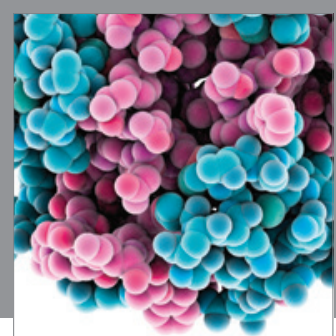

Journal of
Diabetes Research

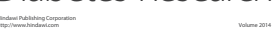

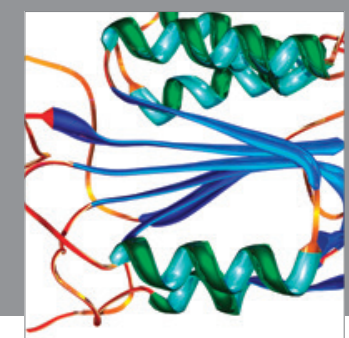

Disease Markers
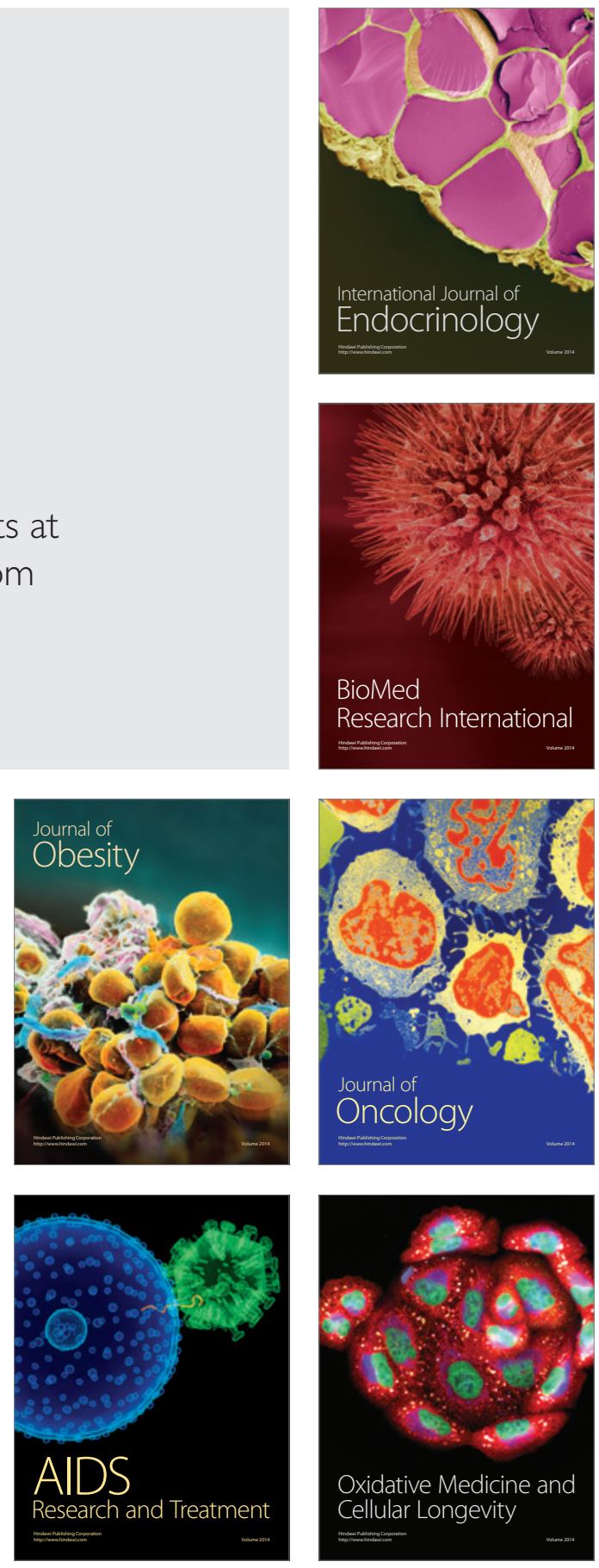